Article

\title{
Complexity and the Sustainable Development Goals: A Computational Intelligence Approach to Support Policy Mix Designs
}

\section{Serdar Türkeli}

United Nations University-Maastricht Economic and Social Research Institute on Innovation and Technology (UNU-MERIT), Maastricht University, Boschstraat No. 24 6211AX Maastricht, the Netherlands; Email: turkeli@merit.unu.edu

\section{ABSTRACT}

In this article, a 3-step neuro-fuzzy expert decision support system is constructed in order to investigate the multifaceted performance interdependencies among 17 SDG performance scores across 162 UN Member States. The direct influence matrix among 17 SDGs, which would be filled by policy experts in interpretive structural modeling, is instead populated by computational intelligence. Results indicate that, the most influential performance drivers are SDG12 (Sustainable Production and Consumption), SDG 9 (Industry, Innovation and Infrastructure) and SDG 11 (Sustainable Cities and Communities) at global level. Yet these findings highlight the importance of establishing and enhancing local infrastructures and communities, innovative and sustainable supply and demand content to increase overall SDGs performance globally. Performance linkages SDG 5 (Gender Equality) and SDG 13 (Climate Action) are global common denominators across localities for positive evolution of overall SDGs performance. Local policy mixes between performance driver and linkage SDGs are recommended by taking eight dependent SDG performances (SDG 10, 16, 15, 8, 6, 17, 7, 2) into account as action contexts. Four autonomous (less influential) SDG performances (SDG 1, 3, 4, 14) remain to be integrated. Conclusions call for a global unity in diversity, local policy mixes by all cities and communities around the globe.

\section{G Open Access}

Received: 19 July 2019

Accepted: 03 January 2020

Published: 06 January 2020

Copyright (c) 2020 by the author(s). Licensee Hapres, London, United Kingdom. This is an open access article distributed under the terms and conditions of Creative Commons Attribution 4.0 International License.
KEYWORDS: complexity; Sustainable Development Goals; mixed method calibration; impact matrix cross-reference multiplication; neuro-fuzzy expert decision support system; computational intelligence; policy mixes

\section{ABBREVIATIONS}

UN, United Nations; SDGs, Sustainable Development Goals; MDGs, Millennium Development Goals; SDSN Sustainable Development Solutions Network; CI, Computational Intelligence; ANNs, Artificial Neural Networks; MLP, Multilayer Perceptron; FES, Fuzzy Expert Systems; research; artificial neural networks; multilayer perceptron; fuzzy set 
MICMAC, The Impact Matrix Cross-Reference Multiplication Applied to a Classification

\section{INTRODUCTION}

In 2014, UN Member States proposed a set of SDGs succeeding the MDGs as a new reference set of targets and goals to be achieved until the year 2030. After being unanimously adopted at the UN Sustainable Development Summit in September 2015, these 17 SDGs came into force on 1 January 2016. The overarching aim of the SDGs, as agreed by the 193 Member States, can be summarized as reaching economic, social and environmental targets, which e.g., will enable poverty elimination in its all forms, sustainable work and lifestyles for all, and a stable resilient planetary life-support system [1].

However, both academic and grey literature argue that it is indeed challenging to define, design, and implement policy mechanisms that would meet these overarching aims without resolving potential conflicts among the targets of sectorial SDGs [2,3]. Authors argue that, for instance, interventions to increase food security (SDG 2) may come at significant costs to the global climate system (SDG 13), in turn; this situation can put food security itself at risk in the long term [1]. On the other hand, "harmony with nature" (e.g., SDGs 6, 12, 13, 14, and 15) do not easily mix with the calls for and the targets of continued global economic growth (SDG 8) [3]. Thus, interactions among SDGs also draw increasing attention of scholars and practitioners and are studied by various scholars and institutions [4-20].

David Le Blanc, in 2015, studied these interactions by using text and network analysis where he processed the SDGs and targets as a term network, in which the links among SDGs exist through the targets that refer to multiple SDGs at the same time [11]. This is a conceptual level interaction analysis using co-occurrences by (text) network analysis. The article contributed to reveal that some thematic areas covered by the SDGs by design are well connected compared to others such as the parts of this term network have weaker connections with the rest of the system. However, according to their analysis, the SDGs as a whole, form a more integrated system than the MDGs, thus, may facilitate policy integration across sectors [8,9].

Institutions have also initiated analyzing SDGs interactions, yet considerable gaps remain, particularly in terms of comprehensiveness (covering all SDGs), quantification of the SDG interlinkages and practical case studies at the national level [13]. One of such projects is run by the Institute for Global Environmental Strategies (IGES), titled "Sustainable Development Goals Interlinkages and Indicators” [13]. Initiated by IGES, the project focuses on SDG indicators and the analysis of the interlinkages among SDG targets since 2015. In IGES analysis, SDGs targets interact with each other in an indivisible way. Achieving one SDG or target may contribute to achieving other SDGs or targets (e.g., 
enhancing food security (SDG 2), decent work (SDG 8), reducing inequalities (SDG 10) would create co-benefits for poverty eradication (SDG 1)). Yet it is also deemed possible that, the pursuit of one target or SDG can create conflict with the achievement of another SDG. Such as, increase in agricultural production to tackle hunger (SDG2) may result in increase in water use for irrigation, which, in turn, may compete with the water demand for achieving universal access to drinkable water (SDG 6) [13-16].

These aforementioned valuable contributions are performed either at concept level or rely on the identification of causal relations among targets and/or SDGs extracted from comprehensive literature reviews and/or qualitative argumentation [17]. Comprehensive quantitative studies also exist. Pradhan et al. conducted a systematic study of SDG interactions by correlation analysis [18]. Türkeli et al. 2019 analyzed the calculated performances on SDGs with hierarchical cluster analysis on 17 SDGs and k-means clustering for all countries in Sub-Saharan Africa [19] using the SDSN and Bertelsmann Stiftung SDG Index data. Dörgő et al. studied interactions among SDGs with a causality analysis of sustainability indicators [20]. Ospina-Forero et al. uses correlation thresholding, chordal information filtering graphs, statistical structure learning and physics-inspired approaches to estimate networks using data from four countries Egypt, Indonesia, Mexico and Turkey [10].

In this article, other than conceptually or theoretically hypothesized or assessed interactions, the actualized SDG performance interactions are at the focus. Therefore, the research question is: To what extent are actualized performances on SDGs interdependent at global level? This research question comes with three consecutive sub research questions: If actualized performances on SDGs are interdependent, how to reveal these interdependencies? What are the differentiating and common quantitative and qualitative features of these interdependencies? Moreover, if such features can be revealed, how to make the best use of this novel information for international development planning and policies?

As an implication of potentially positive co-benefits or negative trade-off interactions among SDGs [1-20], policy integration and especially policy mixes as a solution approach arises as an important research area. Revealing these interactions among SDGs with innovative measures and sound applied research can help ex-ante minimize potential conflicts and setup trade-offs, find further synergies and alternative policy mix instruments for interacting the targets and SDGs in order to realize effective and efficient achievements across all 17 SDG areas. In this article, SDG level interactions will be studied. In order to reveal interdependencies among actualized performances on SDGs, and policy integration and mixes across these SDG areas, analyses have to be based on sound data and methods. This article is organized as follows: in the next section the information on data, materials and methods used and generated are provided. The results of the analysis are provided 
before the following section dedicated to discussions. Discussions section is followed by concluding remarks, recommendations and future research directions towards analyzing the interactions at targets level.

\section{MATERIALS AND METHODS}

The database used in this article, 2019 SDG Index, is compiled by the SDSN and the Bertelsmann Stiftung. The 2019 SDG Index provides a report card for national level performance on the Agenda 2030 and the SDGs. The dataset comes with normalized scores across countries for each SDG, as well as regionally adjusted normalized SDG performance scores (Table 1). Each SDG performance score is calculated by using the same sub-indicator set across SDGs and across countries. In this article, regionally adjusted normalized SDG performance scores of 162 countries are used since data for 31 countries were not available and/or missing.

Table 1. 2019 SDG Index descriptive statistics.

\begin{tabular}{cccccccc}
\hline Descriptive Statistics & N & Range & Min & Max & Mean & Std. Error & Std. Deviation \\
\hline SDG 1 & 162 & 66.175 & 32.667 & 98.841 & 75.262 & 2.101 & 26.738 \\
SDG 2 & 162 & 18.474 & 44.580 & 63.054 & 53.556 & 0.472 & 6.003 \\
SDG 3 & 162 & 48.033 & 44.502 & 92.536 & 70.039 & 1.364 & 17.356 \\
SDG 4 & 162 & 45.805 & 49.365 & 95.169 & 76.903 & 1.381 & 17.576 \\
SDG 5 & 162 & 32.448 & 43.348 & 75.796 & 60.165 & 0.850 & 10.819 \\
SDG 6 & 162 & 36.861 & 50.751 & 87.612 & 67.639 & 1.076 & 13.690 \\
SDG 7 & 162 & 57.301 & 34.936 & 92.237 & 71.128 & 1.854 & 23.594 \\
SDG 8 & 162 & 18.171 & 63.252 & 81.423 & 71.627 & 0.540 & 6.877 \\
SDG 9 & 162 & 54.450 & 14.561 & 69.011 & 35.060 & 1.554 & 19.783 \\
SDG 10 & 162 & 37.550 & 37.109 & 74.658 & 58.999 & 1.086 & 13.818 \\
SDG 11 & 162 & 25.967 & 58.917 & 84.884 & 71.812 & 0.815 & 10.376 \\
SDG 12 & 162 & 39.065 & 53.031 & 92.096 & 77.432 & 1.124 & 14.304 \\
SDG 13 & 162 & 14.956 & 76.130 & 91.086 & 86.611 & 0.325 & 4.131 \\
SDG 14 & 162 & 13.785 & 40.725 & 54.511 & 50.305 & 0.365 & 4.647 \\
SDG 15 & 162 & 23.391 & 48.856 & 72.248 & 64.807 & 0.488 & 6.211 \\
SDG 16 & 162 & 28.066 & 54.204 & 82.271 & 66.012 & 0.824 & 10.486 \\
SDG 17 & 162 & 20.759 & 53.184 & 73.943 & 64.458 & 0.476 & 6.060 \\
\hline
\end{tabular}

Note: 2019 SDG Index codebook, normalized regional scores, indicators and 114 sub-indicators for 17 SDG scores are available from: https://github.com/sdsna/2019GlobalIndex/raw/master/2019GlobalIndexResults.xlsx. Data Source: Sachs et al. [21].

"The SDG Index score and normalized scores by goal can be interpreted as the percentage of achievement... The difference between 100 and countries' scores is therefore the distance in percentage that needs to be completed to achieving the SDGs and goals... The same basket of indicators is used for all countries to generate comparable scores and rankings...” [21]. Data, sub-indicators, indicators for each SDG and the methodology behind the SDG performance scores are independently audited by the 
European Commission Joint Research Center Competence Center on Composite Indicators and Scoreboards in 2019 [22]. Please see [23] for methodological paper. Due to changes in the sub-indicator set and refinements in the methodology after this audit, SDG performance scores cannot be compared across the 2016, 2017 and 2018 datasets, therefore; time dimension cannot be included in this analysis. For the descriptive statistics of the data used in this article, see supplementary file.

In this article, three methods of analysis are utilized sequentially to construct a computational intelligence approach in order to support policy (mix) designs at SDGs level. These methods of analysis are (1) artificial neural network analysis (multilayer perceptron with a backpropagation learning algorithm), (2) four-value fuzzy set calibration for classification, and finally, (3) the impact matrix cross-reference multiplication applied to this classification (MICMAC). By doing so, a neuro-fuzzy expert decision support system is methodologically constructed to support policy (mix) decisions and designs among SDGs aiming at achieving the targets of these SDGs (Figure 1). Figure 1 depicts how this computational intelligence system and analysis operate at a higher level of abstraction.

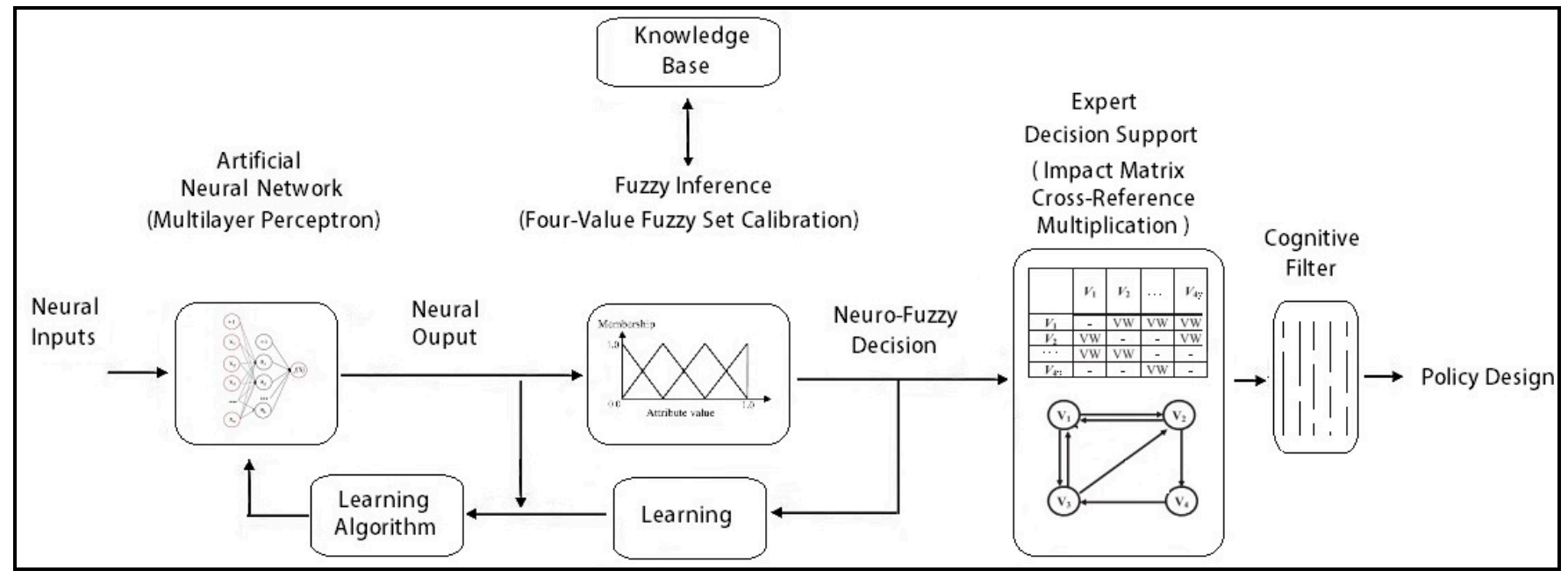

Figure 1. A computational intelligence approach: A neuro-fuzzy expert decision support system.

Assuming 17 SDGs form a complex yet a complete set of a latent system, and since MLPs are fully connected ANNs, in the first step, the computational operation starts with feeding 16 regionally adjusted SDG performance scores of 162 countries into an ANN MLP to approximate each left out SDG performance score. On a rotating basis, this computational operation continues until the least training, testing, holdout errors and their ANN structures are achieved for each SDG. Other than analyzing the synaptic weights, the quantified normalized importance values and percentages of each 16 approximator SDG performance score on each left out and approximated SDG performance score are retrieved from each ANN structure that comes with the least training, testing, holdout errors. These values and percentages, which are 
computed via sensitivity analysis, are used to be able to fill the $17 \times 17$ direct influence matrix after a fixed four-value fuzzy set calibration. For the internal structure of these ANN MLPs, the next section explains the model assumptions, structure, and parameters.

In the second step, by applying four-value fuzzy set calibration to these quantified normalized importance values percentages, a qualitatively transformative classification for interpretability purposes is achieved (e.g., fuzzy inference). In this step, fuzzy calibration is set to fixed four-value calibration in line with the knowledge base of the methodology of 2019 SDG Index. The index considers four bands while assessing a country's progress on a particular indicator [21].

As a result, in the third step, a $17 \times 17$ direct asymmetric influence matrix can be populated by this neuro-fuzzy expert decision support system using these qualitatively transformed classification values of the quantified normalized importance percentages. This matrix defines all impacts among all SDG performance scores, thus, impact matrix cross-reference multiplication revealed the performance drivers, linkages, autonomous and dependent SDG performance scores of this latent system in 4-quandrant. Policy mixes among these SDGs recommended to human policy experts in relation to the dependent and autonomous SDGs by this computational intelligence system and analysis. Such possible policy mixes are substantiated by the literature and practitioners' cases (cognitive filter).

A neuro-fuzzy expert decision support system in this sense refers to the combination of ANN, fuzzy logic, which is introduced by [24], and providing input to direct influence matrix of MICMAC analysis. This is performed to support policy mix decisions and designs of human policy experts. This combination synthesizes ANN, fuzzy logic and populating a structural analysis matrix that combines the constituent indicators of a system. Resulting neuro-fuzzy expert system constrains the individual weaknesses of ANNs, fuzzy logic, unknown nonlinearities by regression analyses, which would come with multi-collinearity issues and/or multi-way interaction effects, and by human policy experts. Thus, it makes use of their best advantages in a computational intelligence approach. The neuro-fuzzy expert decision support system in this sense is a first attempt to construct a multi-step learning machine (if ANN uses a learning algorithm, e.g., backpropagation, as in this article). It finds the parameters of a fuzzy system (e.g., according to fuzzy set rules) by exploiting the approximation techniques, coefficients and parameter estimates from ANN analysis [25-28], and populates the final direct influence matrix among the constituent indicators of the system by computational intelligence to support policy experts. Moreover, negative synaptic weights and positive synaptic weights can suggest tradeoffs and co-benefits, synergies, yet this is out of the scope of this article and part of future research directions. 


\section{First Step: Artificial Neural Networks: Multilayer Perceptron}

In recent years, increasing attention has been given to the development of sophisticated techniques for exploring patterns, regularities, and even rules in datasets. One class of such techniques is artificial neural networks (ANNs). ANNs are utilized in the quest for realizing artificial intelligence (AI) and computational intelligence (CI). Although ANNs are not very near solving complex problems [29], they are versatile, flexible and can be used for modeling (e.g., estimation, regression, and prediction) as well as classification. In the latter case, ANNs are known as universal approximators meaning that they are claimed to be capable of approximating any measurable function to any set degree of accuracy with no ex-ante theoretical constraints [30] in producing a predictive model for one or more dependent variables based on the values of the predictor variables. Comparisons of the performance of various ANN models show that MLP models can be superior to other neural networks models and regression models, as they were able to achieve a relatively lower prediction error in some contexts [31,32]. MLPs can also be competitive with multiple regression models even for relatively small datasets [33-35]. ANNs have theoretical properties, in particular, the ability to detect non-predefined relations such as nonlinear effects and/or interactions, via activation functions. This ability allows researchers to process nonlinear, multidimensional dependencies in data when they want to observe and learn from the data. MLPs are fully connected ANNS in a way that each node in one layer is connected with a certain weight to every node in the following layer. Via sensitivity analysis, the importance of each approximator on an approximated indicator can be computed on a rotating basis while determining the structure of the neural network that comes with the least training, testing and holdout errors.

\section{ANN network architecture}

The ANN network architecture used in this article has these following features:

ANN MLP in this article uses an activation function that connects the weighted sums of neuron in a layer to the values of neurons in the succeeding layer. Hyperbolic tangent activation function is used at the hidden layers. This function receives real-valued items and transforms them to the range $(-1,1)$. The functional form is:

$$
\gamma(\mathrm{c})=\tanh (\mathrm{c})=\left(\mathrm{e}^{\mathrm{c}}-\mathrm{e}^{-\mathrm{c}}\right) /\left(\mathrm{e}^{\mathrm{c}}+\mathrm{e}^{-\mathrm{c}}\right)
$$

To enable deeper learning, two hidden layers are used. Hidden layers contain unobservable network neurons, the number of which is not pre-determined. The ANN architecture contains a second hidden layer; and each hidden neuron in this second layer is a function of the weighted sum of the neurons in the first hidden layer. The same hyperbolic tangent activation function is used in both layers. 
Between the hidden layer and output layer, a sigmoid activation function is used. This function receives real-valued items and transforms them to the range $(0,1)$. The functional form is:

$$
y(c)=1 /\left(1+e^{-c}\right)
$$

Inputs are normalized. Thus, normalized rescaling of dependent variables is also performed which is the required rescaling method for dependent variables if the output layer uses the sigmoid activation function, as it is the case in this article. To ensure that all rescaled dependent variable values fall within the range of the activation function, a correction parameter applied to the rescaling formula with a default value of 0.02 , thus, final values fall between the range of the utilized sigmoid activation function, 0 and 1 . The formula is:

$$
[x-(\min -\varepsilon)] /[(\max +\varepsilon)-(\min -\varepsilon)]
$$

\section{Partition dataset and training}

The dataset is partitioned into training sample (the data used to train the ANN and to obtain a model), testing sample (an independent set of data used to trace errors during training to prevent overtraining), and holdout sample (independent set of data used to assess the ability of the final neural network considering the error estimates for the holdout sample). This error provides an estimate of the predictive ability of the model because the holdout sample is not used to build the model. Cases are randomly assigned to each sample as training sample ( $60 \%)$, testing sample ( 20\%) and holdout sample ( 20\%). Batch training, which is most useful for smaller datasets, is used to update the synaptic weights, with the condition that after processing all training data in the training dataset. As the optimization algorithm, the scaled conjugate gradient method is used to estimate these synaptic weights, the assumptions of which apply only to batch training. Training options for the scaled conjugate gradient algorithm are initial lambda 0.0000005 (which should be less than 0.000001), initial sigma, 0.00005 (which should be less than 0.0001), interval center 0 , interval offset \pm 0.5 . These values define the interval in which the weight vectors are randomly generated by simulated annealing in finding the global minimum and moving away from local minimums during the optimization algorithm [36].

These theoretical and parametrical settings introduce a cost of reduced interpretability of the model output [30]. ANNs in this sense are black boxes and the difficulty in interpreting the possible relationships between indicators emerge. In this article, this interpretability cost is handled by two other quantitative and qualitative approaches, explained in the next subsections. 


\section{Second Step: Four-Value Fuzzy Set Calibration for Qualitatively Transformative Classification}

Constructing a neuro-fuzzy expert decision support system in this article continues with applying fuzzy "if - then" rules to the outputs of ANN MLP. The four-value fuzzy set scheme is used. This scheme uses fixed numerical membership values $0,0.33,0.67$, and 1.0 to indicate "fully out", "more out than in", "more in than out", and "fully in", respectively [37]. Such a scheme is especially useful for the situations where researchers have a considerable amount of information about cases (e.g., well documented codebook from data provider) yet the nature of the evidence may not be identical across cases. In this sense, the integrated application of computational intelligence and soft computing prior to structural analysis contributes to constraining the impact of interpretability issues by providing more interpretable models and/or outputs. ANNs with fuzzy logic are example of such soft computing since they provide solutions to problems, which are difficult to be solved with complete logical certainty. Soft computing approaches to AI, such as fuzzy systems, grey system theories, evolutionary computation, complements the interpretability. Thus, the fuzzy expert systems (FES) and ANNs share common origin and purposes, and can be integrated or sequentially implemented. In this way, they support carrying out a logical reasoning by combining the quantitative and qualitative information and meta-knowledge in simulating AI [38].

Third Step: Impact Matrix Cross-Reference Multiplication Applied to a Neuro-Fuzzy Classification

The Impact Matrix Cross-Reference Multiplication Applied to a Classification (MICMAC) [41,42] is a type of interpretive structural analysis, which aims to determine the most important variables of a system. Analysis uses a matrix which establishes the relations among these variables (e.g., procedure is to first defining the relevant variables by experts (in this article, SDGs), specifying the relations between the variables by experts (in this article by ANN plus fuzzy set analysis and output); identifying the key variables among all the variables proposed by the expert(s) by MICMAC method. This analysis is used in decision making to achieve desired objectives. Identification of key variables which could influence the system is necessary in order to develop appropriate policies and strategies [41,42]. The methodology for identification of key variables based on direct as well as indirect inter-relationships may be difficult for experts, and not be clearly or immediately visible. Classification of the variables with respect to different types of significance by each one (cross-reference) helps observing these relationships. The relationships are also presented by using the influence (driving power)-dependence matrix. MICMAC has been increasingly used in a number of applications in various domains 
since the middle 1980s by businesses as well as on society related topics (e.g., in measuring the key guidelines of third party logistics services providers; in environmental trend analysis, for the effectiveness of information system; waste management [43,44]. In this article, the computational inputs to this impact matrix are intended as expert decision support.

\section{RESULTS}

\section{ANN MLP: Normalized Importance Values}

The ANN MLP analysis in this article is based on the combined training and testing samples leading to normalized importance values and percentages for each approximator SDG score for each approximated SDG score as a system on a rotating basis for each SDG (Table 2). Table 2 below demonstrates the model specifications and the relative errors (0.001) as the average overall relative error (relative to the mean model).

Table 2. Model summaries, Training ( 60\%), Testing ( 20\%) and Holdout ( 20\%) and relative errors.

\begin{tabular}{|c|c|c|c|c|c|c|c|c|c|c|c|c|}
\hline \multirow{2}{*}{$\begin{array}{c}\text { Predicted } \\
\text { SDG }\end{array}$} & \multirow{2}{*}{$\begin{array}{c}\text { Sample } \\
\text { Size }\end{array}$} & \multicolumn{2}{|c|}{ Training } & \multicolumn{2}{|c|}{ Testing } & \multicolumn{2}{|c|}{ Holdout } & \multirow{2}{*}{$\begin{array}{c}\text { Training } \\
\text { Sum of } \\
\text { Squares } \\
\text { Error } \\
\end{array}$} & \multirow{2}{*}{$\begin{array}{c}\text { Training } \\
\text { Relative } \\
\text { Error }\end{array}$} & \multirow{2}{*}{$\begin{array}{c}\text { Testing } \\
\text { Sum of } \\
\text { Squares } \\
\text { Error } \\
\end{array}$} & \multirow{2}{*}{$\begin{array}{c}\text { Testing } \\
\text { Relative } \\
\text { Error }\end{array}$} & \multirow{2}{*}{$\begin{array}{c}\text { Holdout } \\
\text { Relative } \\
\text { Error }\end{array}$} \\
\hline & & $\mathrm{N}$ & $\&$ & $\mathbf{N}$ & $\&$ & $\mathbf{N}$ & $\&$ & & & & & \\
\hline SDG1 & N (162) & 100 & $61.70 \%$ & 27 & $16.70 \%$ & 35 & $21.60 \%$ & 0.006 & 0.001 & 0.002 & 0.001 & 0.001 \\
\hline SDG2 & N (162) & 90 & $55.6 \%$ & 39 & $24.1 \%$ & 33 & $20.4 \%$ & 0.003 & 0.001 & 0.001 & 0.001 & 0.001 \\
\hline SDG3 & N (162) & 99 & $61.10 \%$ & 32 & $19.80 \%$ & 31 & $19.10 \%$ & 0.003 & 0.001 & 0.001 & 0 & 0.001 \\
\hline SDG4 & N (162) & 95 & $58.60 \%$ & 33 & $20.40 \%$ & 34 & $21.00 \%$ & 0.006 & 0.001 & 0.002 & 0.001 & 0.001 \\
\hline SDG5 & N (162) & 97 & $59.90 \%$ & 37 & $28.80 \%$ & 28 & $17.30 \%$ & 0.004 & 0.001 & 0.002 & 0.001 & 0.001 \\
\hline SDG6 & N (162) & 90 & $55.60 \%$ & 30 & $18.50 \%$ & 42 & $25.90 \%$ & 0.005 & 0.001 & 0.002 & 0.001 & 0.001 \\
\hline SDG7 & N (162) & 95 & $58.60 \%$ & 33 & $20.40 \%$ & 34 & $21.00 \%$ & 0.006 & 0.001 & 0.002 & 0.001 & 0.001 \\
\hline SDG8 & N (162) & 104 & $64.20 \%$ & 30 & $18.50 \%$ & 28 & $17.30 \%$ & 0.005 & 0.001 & 0.002 & 0.001 & 0.001 \\
\hline SDG9 & N (162) & 99 & $61.10 \%$ & 32 & $19.80 \%$ & 31 & $19.10 \%$ & 0.004 & 0.001 & 0.001 & 0.001 & 0.001 \\
\hline SDG10 & N (162) & 98 & $60.50 \%$ & 35 & $21.60 \%$ & 29 & $17.90 \%$ & 0.004 & 0.001 & 0.002 & 0.001 & 0.001 \\
\hline SDG11 & N (162) & 86 & $53.10 \%$ & 29 & $17.90 \%$ & 47 & $29.00 \%$ & 0.005 & 0.001 & 0.002 & 0.001 & 0.001 \\
\hline SDG12 & N (162) & 106 & $65.40 \%$ & 21 & $13.00 \%$ & 35 & $21.60 \%$ & 0.005 & 0.001 & 0.001 & 0.001 & 0.001 \\
\hline SDG13 & N (162) & 96 & $59.30 \%$ & 33 & $20.40 \%$ & 33 & $20.40 \%$ & 0.003 & 0.001 & 0.001 & 0.001 & 0.001 \\
\hline SDG14 & N (162) & 104 & $64.20 \%$ & 29 & $17.90 \%$ & 29 & $17.90 \%$ & 0.005 & 0.001 & 0.001 & 0.001 & 0.001 \\
\hline SDG15 & N (162) & 87 & $53.70 \%$ & 29 & $17.90 \%$ & 46 & $28.40 \%$ & 0.003 & 0.001 & 0.001 & 0.001 & 0.001 \\
\hline SDG16 & N (162) & 94 & $58.00 \%$ & 35 & $21.60 \%$ & 33 & $20.40 \%$ & 0.004 & 0.001 & 0.001 & 0.001 & 0.001 \\
\hline SDG17 & $\mathrm{N}(162)$ & 91 & $56.20 \%$ & 38 & $23.50 \%$ & 33 & $20.40 \%$ & 0.002 & 0.001 & 0.001 & 0.001 & 0.001 \\
\hline
\end{tabular}

For demonstration purposes in Figure 2 and Table 3 only the results for SDG 9 are provided (Figure 2 and Table 3). Please see supplementary file for all 17 ANNS, model specifications, visual diagrams, parameter estimates, and computational logs. 
- Synaptic Weight >0

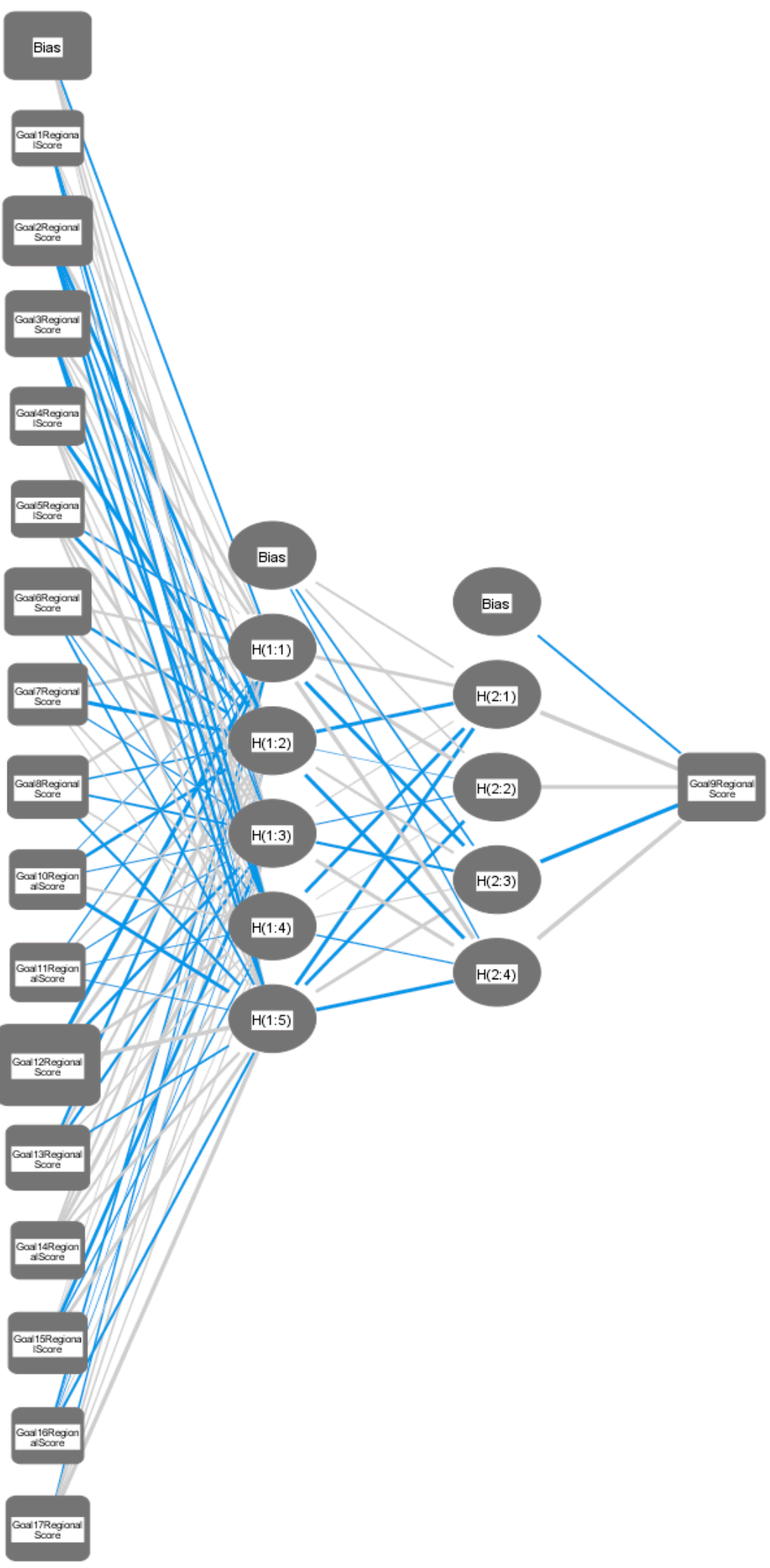

Hidden layer activation function: Hyperbolic tangent

Output layer activation function: Sigmoid

Figure 2. ANN MLP network architecture for SDG 9. 
Table 3. Normalized importance values and percentages of other SDGs for approximating SDG 9 performance score.

\begin{tabular}{lrr}
\hline Independent Variable Importance by Sensitivity Analysis & \\
\hline SDG & Importance & Normalized Importance \\
\hline SDG 1 & 0.011 & $5.3 \%$ \\
SDG 2 & 0.117 & $57.7 \%$ \\
SDG 3 & 0.087 & $42.9 \%$ \\
SDG 4 & 0.029 & $14.1 \%$ \\
SDG 5 & 0.017 & $8.4 \%$ \\
SDG 6 & 0.098 & $48.5 \%$ \\
SDG 7 & 0.056 & $27.8 \%$ \\
SDG 8 & 0.064 & $31.4 \%$ \\
SDG 10 & 0.040 & $19.7 \%$ \\
SDG 11 & 0.031 & $15.4 \%$ \\
SDG 12 & 0.202 & $100.0 \%$ \\
SDG 13 & 0.081 & $40.3 \%$ \\
SDG 14 & 0.023 & $11.3 \%$ \\
SDG 15 & 0.053 & $26.2 \%$ \\
SDG 16 & 0.013 & $6.3 \%$ \\
SDG 17 & 0.080 & $39.4 \%$ \\
\hline
\end{tabular}

\section{Four-Value Fuzzy Set Calibration: Qualitatively Transformative Classification}

Table 4 below represents the normalized importance percentages of each SDG performance score for other SDG performance scores. This is the compilation of normalized importance percentage outputs from ANN MLP and sensitivity analyses in the first step (Table 4).

Table 4. Four-value fuzzy set calibration and classification input in percentages.

\begin{tabular}{|c|c|c|c|c|c|c|c|c|c|c|c|c|c|c|c|c|c|}
\hline $\mathrm{NI} / \mathrm{I}$ & $\begin{array}{c}\text { SDG } \\
1 \\
\end{array}$ & $\begin{array}{c}\text { SDG } \\
2 \\
\end{array}$ & $\begin{array}{c}\text { SDG } \\
\mathbf{3} \\
\end{array}$ & $\begin{array}{c}\text { SDG } \\
\mathbf{4} \\
\end{array}$ & $\begin{array}{c}\text { SDG } \\
5 \\
\end{array}$ & $\begin{array}{c}\text { SDG } \\
6 \\
\end{array}$ & $\begin{array}{c}\text { SDG } \\
7 \\
\end{array}$ & $\begin{array}{c}\text { SDG } \\
8 \\
\end{array}$ & $\begin{array}{c}\text { SDG } \\
9 \\
\end{array}$ & $\begin{array}{c}\text { SDG } \\
10 \\
\end{array}$ & $\begin{array}{c}\text { SDG } \\
11 \\
\end{array}$ & $\begin{array}{c}\text { SDG } \\
12 \\
\end{array}$ & $\begin{array}{c}\text { SDG } \\
13 \\
\end{array}$ & $\begin{array}{c}\text { SDG } \\
14 \\
\end{array}$ & $\begin{array}{c}\text { SDG } \\
15 \\
\end{array}$ & $\begin{array}{c}\text { SDG } \\
16 \\
\end{array}$ & $\begin{array}{c}\text { SDG } \\
17 \\
\end{array}$ \\
\hline SDG1 & & 50.6 & 59.3 & 97.6 & 12.3 & 69.5 & 89.2 & 16.5 & 5.30 & 100 & 33.7 & 22.9 & 24.6 & 23.1 & 75.1 & 21.4 & 66.7 \\
\hline SDG2 & 25.6 & & 63.5 & 6.80 & 4.70 & 60.7 & 41.2 & 23.2 & 57.7 & 32.0 & 7.30 & 26.6 & 64.8 & 28.3 & 61.3 & 73.1 & 71.0 \\
\hline SDG3 & 16.0 & 24.8 & & 52.1 & 35.0 & 30.1 & 39.9 & 21.9 & 42.9 & 84.3 & 46.1 & 45.5 & 44.6 & 21.4 & 17.1 & 83.4 & 40.2 \\
\hline SDG4 & 100 & 5.60 & 31.0 & & 51.1 & 57.1 & 71.9 & 4.80 & 14.1 & 82.1 & 9.90 & 5.20 & 23.0 & 2.90 & 37.5 & 60.8 & 39.0 \\
\hline SDG5 & 20.9 & 70.2 & 49.3 & 61.9 & & 37.8 & 43.3 & 72.1 & 8.40 & 74.7 & 93.7 & 12.0 & 85.2 & 7.90 & 85.5 & 57.2 & 52.0 \\
\hline SDG6 & 5.50 & 52.0 & 39.2 & 33.2 & 83.3 & & 36.2 & 100 & 48.5 & 1.80 & 80.9 & 18.0 & 34.7 & 11.2 & 33.3 & 33.5 & 25.7 \\
\hline SDG7 & 80.2 & 79.8 & 7.00 & 50.5 & 24.0 & 6.80 & & 37.6 & 27.8 & 18.1 & 9.50 & 22.8 & 8.40 & 14.4 & 36.7 & 6.80 & 60.8 \\
\hline SDG8 & 12.9 & 19.1 & 20.9 & 30.4 & 73.2 & 48.1 & 25.0 & & 31.4 & 57.9 & 100 & 11.1 & 38.1 & 63.8 & 85.5 & 96.8 & 70.3 \\
\hline SDG9 & 27.2 & 34.3 & 21.4 & 47.1 & 27.3 & 56.2 & 57.9 & 80.0 & & 74.4 & 64.8 & 38.8 & 8.20 & 72.7 & 90.4 & 94.2 & 49.3 \\
\hline SDG10 & 7.20 & 40.8 & 14.5 & 25.3 & 57.1 & 53.2 & 37.4 & 13.6 & 19.7 & & 4.20 & 13.0 & 11.1 & 100 & 16.7 & 67.0 & 54.2 \\
\hline SDG11 & 34.5 & 41.9 & 4.10 & 55.6 & 85.8 & 100 & 47.7 & 87.1 & 15.4 & 10.7 & & 12.4 & 73.0 & 47.6 & 61.3 & 77.1 & 17.4 \\
\hline
\end{tabular}


Table 4. Cont.

\begin{tabular}{|c|c|c|c|c|c|c|c|c|c|c|c|c|c|c|c|c|c|}
\hline $\mathrm{NI} / \mathbf{P}>\mathrm{V}$ & $\begin{array}{c}\text { SDG } \\
1 \\
\end{array}$ & $\begin{array}{c}\text { SDG } \\
2 \\
\end{array}$ & $\begin{array}{c}\text { SDG } \\
\mathbf{3} \\
\end{array}$ & $\begin{array}{c}\text { SDG } \\
4 \\
\end{array}$ & $\begin{array}{c}\text { SDG } \\
5 \\
\end{array}$ & $\begin{array}{c}\text { SDG } \\
6 \\
\end{array}$ & $\begin{array}{c}\text { SDG } \\
7 \\
\end{array}$ & $\begin{array}{c}\text { SDG } \\
8 \\
\end{array}$ & $\begin{array}{c}\text { SDG } \\
9 \\
\end{array}$ & $\begin{array}{c}\text { SDG } \\
10 \\
\end{array}$ & $\begin{array}{c}\text { SDG } \\
11 \\
\end{array}$ & $\begin{array}{c}\text { SDG } \\
12 \\
\end{array}$ & $\begin{array}{c}\text { SDG } \\
13 \\
\end{array}$ & $\begin{array}{c}\text { SDG } \\
14 \\
\end{array}$ & $\begin{array}{c}\text { SDG } \\
15 \\
\end{array}$ & $\begin{array}{c}\text { SDG } \\
16 \\
\end{array}$ & $\begin{array}{c}\text { SDG } \\
17 \\
\end{array}$ \\
\hline SDG12 & 48.4 & 100 & 100 & 100 & 100 & 78.8 & 100 & 70.3 & 100 & 62.9 & 49.8 & & 77.9 & 39.7 & 86.6 & 100 & 22.7 \\
\hline SDG13 & 16.5 & 26.9 & 54.3 & 26.8 & 64.6 & 41.5 & 19.3 & 18.3 & 40.3 & 74.1 & 37.9 & 100 & & 64.2 & 100. & 84.2 & 100 \\
\hline SDG14 & 33.0 & 60.5 & 22.1 & 25.2 & 30.7 & 6.20 & 28.6 & 28.5 & 11.3 & 83.6 & 31.9 & 3.50 & 22.3 & & 27.5 & 3.40 & 32.3 \\
\hline SDG15 & 19.6 & 16.0 & 58.1 & 48.0 & 98.6 & 30.7 & 30.2 & 86.6 & 26.2 & 72.7 & 38.3 & 40.1 & 100 & 8.30 & & 5.40 & 79.8 \\
\hline SDG16 & 35.9 & 13.6 & 7.80 & 25.1 & 37.2 & 51.3 & 55.7 & 42.7 & 6.30 & 93.3 & 60.5 & 16.6 & 32.6 & 54.2 & 50.9 & & 20.0 \\
\hline SDG17 & 18.5 & 57.0 & 16.3 & 42.0 & 61.1 & 40.1 & 25.6 & 42.3 & 39.4 & 39.8 & 8.90 & 25.2 & 85.0 & 46.5 & 64.2 & 33.4 & \\
\hline
\end{tabular}

Four-value fuzzy sets calibration is applied on these percentages following the IF-THEN rule: IF (Value $>66.7 \%$, 3, IF (Value $>33.3 \%$, 2 , ELSE 1)) for a qualitatively transformative classification.

\section{Impact Matrix Cross-Reference Multiplication Applied to Neuro-Fuzzy Classification}

The matrix of direct influence (MDI)

MDI describes the relations of direct influences between the indicators defining the system, here SDGs. The input to this matrix is equivalent to the output of four-value fuzzy set calibration classifier in the second step. Please note that qualitative transformation of "no influence", "weak", "moderate" and "strong influence" is enabled by this four-value fuzzy set calibration as classification (Table 5). Thus, "3" denotes strong influence; "2", moderate, and "1", weak influence. The result of this qualitatively transformative calibration for classification is given in Table 5 .

Table 5. Four-Value Fuzzy Set Calibration as Input to Matrix of Direct Influences (MDI) *.

\begin{tabular}{|c|c|c|c|c|c|c|c|c|c|c|c|c|c|c|c|c|c|}
\hline $\begin{array}{c}\mathrm{NI} / \mathrm{P}> \\
\mathbf{v} \\
\end{array}$ & $\begin{array}{c}\text { SDG } \\
1 \\
\end{array}$ & $\begin{array}{c}\text { SDG } \\
2 \\
\end{array}$ & $\begin{array}{c}\text { SDG } \\
3 \\
\end{array}$ & $\begin{array}{c}\text { SDG } \\
4 \\
\end{array}$ & $\begin{array}{c}\text { SDG } \\
5 \\
\end{array}$ & $\begin{array}{c}\text { SDG } \\
6 \\
\end{array}$ & $\begin{array}{c}\text { SDG } \\
7 \\
\end{array}$ & $\begin{array}{c}\text { SDG } \\
8 \\
\end{array}$ & $\begin{array}{c}\text { SDG } \\
9 \\
\end{array}$ & $\begin{array}{l}\text { SDG } \\
10 \\
\end{array}$ & $\begin{array}{l}\text { SDG } \\
11 \\
\end{array}$ & $\begin{array}{l}\text { SDG } \\
12 \\
\end{array}$ & $\begin{array}{l}\text { SDG } \\
13 \\
\end{array}$ & $\begin{array}{l}\text { SDG } \\
14 \\
\end{array}$ & $\begin{array}{l}\text { SDG } \\
15 \\
\end{array}$ & $\begin{array}{l}\text { SDG } \\
16 \\
\end{array}$ & $\begin{array}{l}\text { SDG } \\
17 \\
\end{array}$ \\
\hline SDG1 & 0 & 2 & 2 & 3 & 1 & 3 & 3 & 1 & 1 & 3 & 2 & 1 & 1 & 1 & 3 & 1 & 2 \\
\hline SDG2 & 1 & 0 & 2 & 1 & 1 & 2 & 2 & 1 & 2 & 1 & 1 & 1 & 2 & 1 & 2 & 3 & 3 \\
\hline SDG3 & 1 & 1 & 0 & 2 & 2 & 1 & 2 & 1 & 2 & 3 & 2 & 2 & 2 & 1 & 1 & 3 & 2 \\
\hline SDG4 & 3 & 1 & 1 & 0 & 2 & 2 & 3 & 1 & 1 & 3 & 1 & 1 & 1 & 1 & 2 & 2 & 2 \\
\hline SDG5 & 1 & 3 & 2 & 2 & 0 & 2 & 2 & 3 & 1 & 3 & 3 & 1 & 3 & 1 & 3 & 2 & 2 \\
\hline SDG6 & 1 & 2 & 2 & 1 & 3 & 0 & 2 & 3 & 2 & 1 & 3 & 1 & 2 & 1 & 1 & 2 & 1 \\
\hline SDG7 & 3 & 3 & 1 & 2 & 1 & 1 & 0 & 2 & 1 & 1 & 1 & 1 & 1 & 1 & 2 & 1 & 2 \\
\hline SDG8 & 1 & 1 & 1 & 1 & 3 & 2 & 1 & 0 & 1 & 2 & 3 & 1 & 2 & 2 & 3 & 3 & 3 \\
\hline SDG9 & 1 & 2 & 1 & 2 & 1 & 2 & 2 & 3 & 0 & 3 & 2 & 2 & 1 & 3 & 3 & 3 & 2 \\
\hline SDG10 & 1 & 2 & 1 & 1 & 2 & 2 & 2 & 1 & 1 & 0 & 1 & 1 & 1 & 3 & 1 & 3 & 2 \\
\hline SDG11 & 2 & 2 & 1 & 2 & 3 & 3 & 2 & 3 & 1 & 1 & 0 & 1 & 3 & 2 & 2 & 3 & 1 \\
\hline SDG12 & 2 & 3 & 3 & 3 & 3 & 3 & 3 & 3 & 3 & 2 & 2 & 0 & 3 & 2 & 3 & 3 & 1 \\
\hline SDG13 & 1 & 1 & 2 & 1 & 2 & 2 & 1 & 1 & 2 & 3 & 2 & 3 & 0 & 2 & 3 & 3 & 3 \\
\hline SDG14 & 1 & 2 & 1 & 1 & 1 & 1 & 1 & 1 & 1 & 3 & 1 & 1 & 1 & 0 & 1 & 1 & 1 \\
\hline SDG15 & 1 & 1 & 2 & 2 & 3 & 1 & 1 & 3 & 1 & 3 & 2 & 2 & 3 & 1 & 0 & 1 & 3 \\
\hline SDG16 & 2 & 1 & 1 & 1 & 2 & 2 & 2 & 2 & 1 & 3 & 2 & 1 & 1 & 2 & 2 & 0 & 1 \\
\hline SDG17 & 1 & 2 & 1 & 2 & 2 & 2 & 1 & 2 & 2 & 2 & 1 & 1 & 3 & 2 & 2 & 2 & 0 \\
\hline
\end{tabular}

* NI: Normalized Importance; P: Predicted; 3 denotes, strong influence; 2, moderate; and 1, weak influence. 


\section{Direct influence/dependence map}

This map is set by the matrix of direct influences (MDI) (Figure 3).

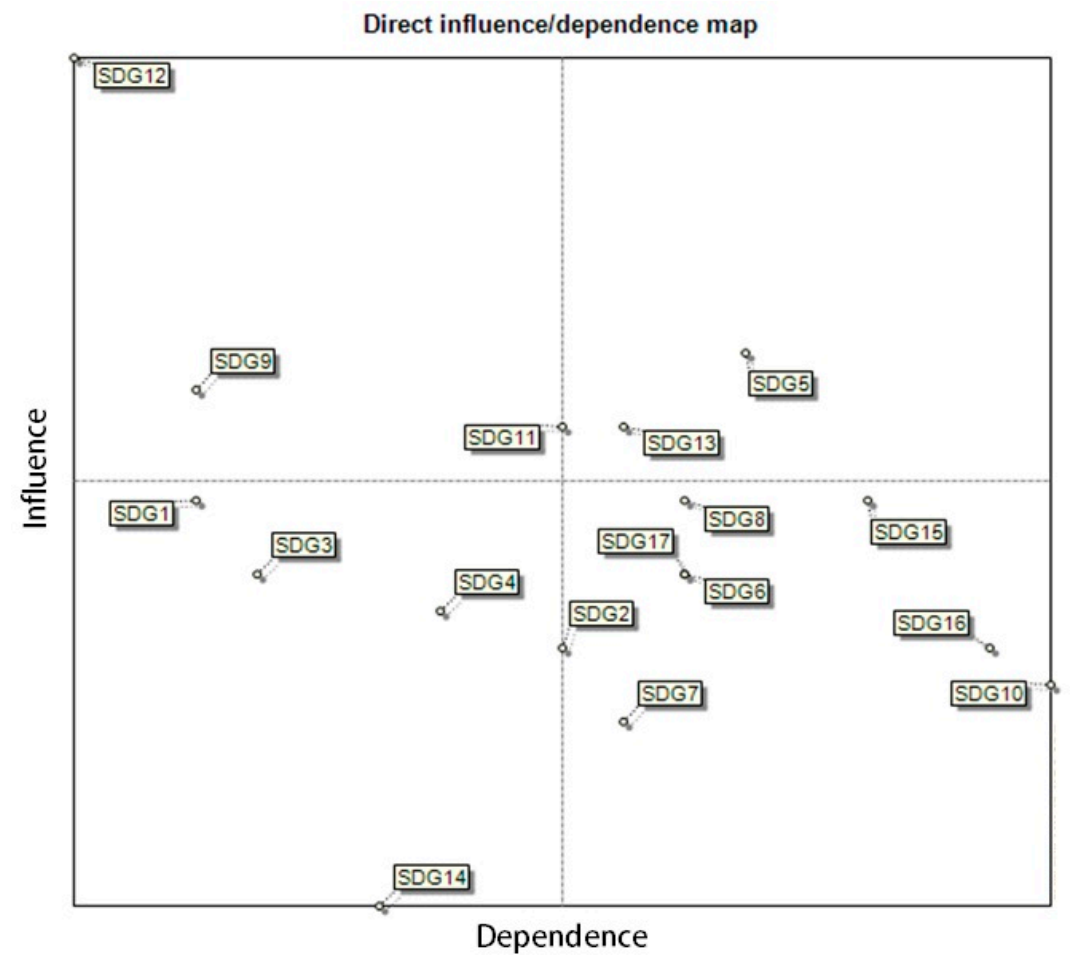

Figure 3. Direct influence/dependence map.

\section{Direct influence graph}

The direct influence graph below is set by the matrix of direct influences (MDI) (Figure 4).

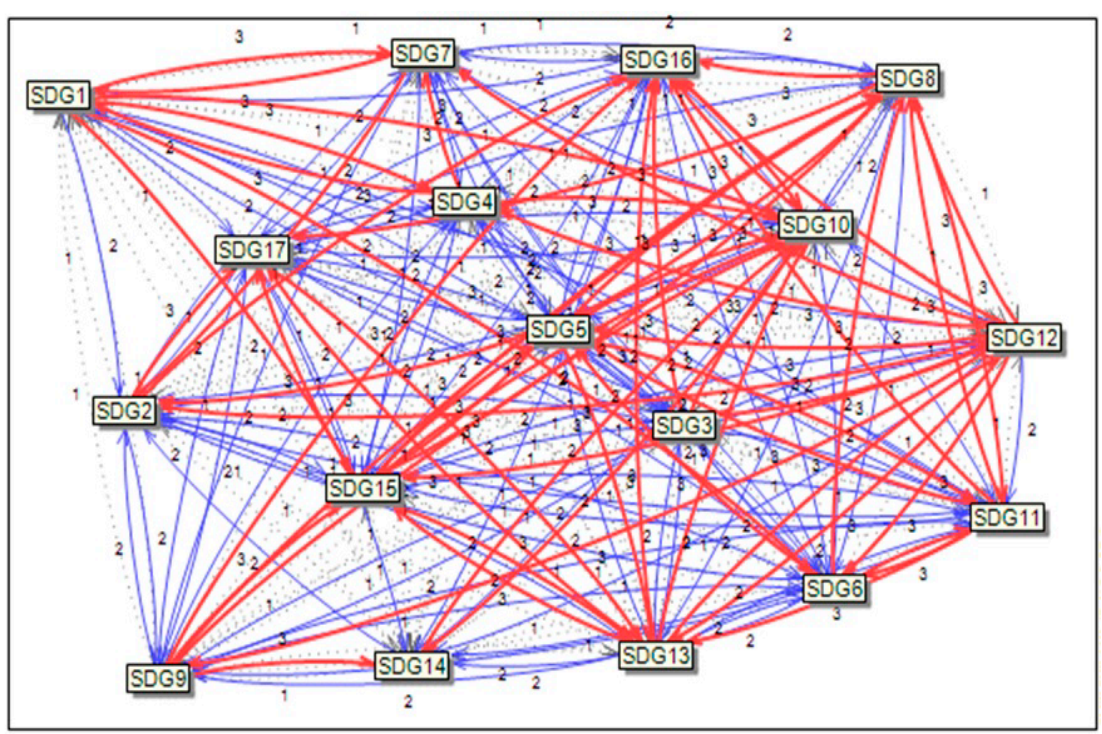

\footnotetext{
Weakest influences

- Weak influences

- Moderate influences

- Relatively strong influences

- Strongestinfluences
}

Figure 4. Direct influence graph. 


\section{DISCUSSION}

For overall system performance, the most influential drivers are SDG12 (Sustainable Production and Consumption), SDG 9 (Industry, Innovation, and Infrastructure) and SDG 11 (Sustainable Cities and Communities). The analysis also suggests that SDG 11 (Sustainable Cities and Communities) locates at the vicinity of influence-dependence equilibrium of the overall SDG performance system. These driver SDGs are more capable of influencing the performance of other SDGs. The performance on these driver and linkage SDGs increases the performance of the system as a whole. Thus, they are important SDGs for overall system performance. Yet, policy integration and policy mixes among these SDGs are recommended in relation to the dependent and autonomous SDG performances to create guided co-benefits and synergies. Similarly, SDG 5 (Gender Equality) and SDG 13 (Climate Action) cluster in influential yet relatively more dependent quadrant, as performance linkages of the SDGs performance system. These linkage SDGs are essential to the evolution of the system globally. If the performance driver and linkage SDGs can be well-addressed with capable policy mixes in relation to the dependent and autonomous SDGs, this would provide reliable and inclusive foundations for increasing the performance of dependent SDGs (SDG 2, 6, 7, 8, 10, 15, 16, 17) and autonomous SDGs (SDG 1, 3, 4, 14). Thus, the performance of overall SDGs system [45].

One example relevant to this finding on drivers and linkages is the SDG Fund, which is an international multi-donor and multi-agency development mechanism created in 2014 by the UN to support sustainable development activities through integrated and multidimensional joint programmes. The programmes of SDG Fund embed three crosscutting issues: sustainability, gender equality and public-private partnerships [46]. Two of them are determined as performance drivers (SDG 12) and linkages (SDG 5), and the last one, as a dependent SDG 17 (Partnerships for the Goals) in this article. Another example is, according to this analysis, SDG 2 performance, which is a dependent one on other SDG performances, as SDG 6 and SDG 15 scores are. This finding suggests that the issues in these policy areas could be deliberately, simultaneously, and constructively addressed within a policy mix.

This finding is supported by the literature: e.g., the management of phosphorus use to intensify food production to address SDG 2 (zero hunger) and minimizing ecosystem impacts (SDG 15 Life on land, SDG 6 Water and Sanitation) is discussed, e.g., in terms of ensuring food security in poorer nations by redistributing phosphorus use from excess to deficit regions [47]. In the literature, comparable considerations are also found for the nitrogen cycle [48], water [49], land-use change [50] and pollution levels. On this finding, the SDG Fund operates in 22 countries to pilot integrated approaches to SDGs in sectorial areas, targets inclusive 
economic growth (SDG 8) for poverty eradication, food security and nutrition and water and sanitation [46]. Leading role for such a policy mix design and implementation and for localization guidelines at international level would be on IFAD (International Fund for Agricultural Development), WFP (World Food Programme) and FAO (The Food and Agriculture Organization of the United Nations).

SDG 16, relating to Peace, Justice and Strong Institutions and sustainable governance is also dependent on other SDG performances according to the analysis in this article. The integration of environmental and socio-economic policies at all levels and among all SDGs would necessitate interacting governance mechanisms.

It is intuitive that SDG 10 (Reduced Inequalities) is highly dependent and SDG 14 (Life below water) is disconnected from the overall system performance, which is a finding also supported by the grey literature [21,51]. The proximity of SDG 17 (Partnerships for the Goals) to linkages quadrant (consisting of indicators for the evolution of system performance) is also a promising finding because partnerships for the goals are expected to bring forward potential positive performance spillovers. The detection of eight dependent SDGs, the number of them, and the thematic areas they are in also support the debates in the aforementioned literature on SDG interactions with respect to the existence of trade-offs.

The overall simplified output of this computational intelligence approach can be interpreted as designing policy mixes as: (Driver SDGs) for (Linkage SDGs) to (also) address (Dependent SDGs). This main recommendation is a call for policy mixes among drivers (SDGs 12, 9, 11) which come with high impact on the other SDGs performances, thus, with a high priority for policy mixes, and linkages (SDG 5, 13), which are important for the evolution of the overall system performance. Yet with a view on increasing and/or at least not reducing, the performance of dependent SDGs such that policy mixes on driver and linkage SDGs need to consider and ensure the potential positive impacts on the performance of dependent SDGs.

To exemplify this main recommendation, for instance, a policy mix design among SDG 9 (Industry, Innovation, and Infrastructure) guided towards SDG 13 (Climate Action) in order to address challenges related to SDG 15 (Life on Land) and/or SDG 14 (Life below Water) can be given as an example. This policy mix activates and increases the performance of so far autonomous SDG 14. Another example for a policy mix could be Responsible Innovation (Mix between drivers SDG 12 and 9) for Gender Equality (SDG 5 Linkages) to address (Dependent SDGs) e.g., decent work and economic growth (SDG 8), with a broader aim of reducing inequalities (SDG 10). These policy mixes emphasize guided positive synergies other than hands-off trade-offs among SDGs. Yet in all, SDG 4 (Quality Education) should be included in these policy mixes as both beneficiary, recipient and supporter, enabler of innovations since 
autonomous SDG 4 performance remains to be adapted and integrated to the overall system performance in order to increase it.

Finally, the aim of this analysis is not to reveal the exact causal mechanisms through which the influence of one SDG is carried onto the other SDGs. Thus, these findings require further in-depth qualitative research and process tracing which can contribute to substantiate, support, challenge, or refute these findings.

\section{CONCLUSIONS}

Revealing performance influences and interdependencies among SDGs and indicating the policy areas that require informed policy interventions and mixes are deemed contributory towards the achievement of SDGs. The neuro-fuzzy expert decision support system and analysis in this article as a computational intelligence approach, uses data of 162 countries by 17 SDGs. Findings stress the importance of performance drivers and linkages, as the common denominators across so-called nations and localities. The importance of local policy mixes and actions among driver and linkage SDGs in order to create co-benefits and synergies in relation to dependent SDGs and autonomous SDGs is also emphasized such that dependent SDGs are prone to be negatively influenced by other SDGs, even though those other SDGS are performance drivers. Similarly, performance on SDG 4 (Quality Education) does not drive the overall system performance, which calls for educational rethinking and reform action, and duality of education as both beneficiary and user of sustainable innovations and contributor to developing sustainable innovations. These findings can be used to support collective reflection processes of working committees made up of human policy experts while conducting an in-depth interpretive qualitative structural analysis.

For future research directions, similar analyses incorporating a temporal dimension can be performed at the targets and national level to support policy experts' decision-making processes. It is true that countries may have different priorities and targets, and are likely to invest in different emphases on various SDGs and targets depending on their national geo-historical context of political and economic priorities. For instance, according to 2019 SDG Index scores, Denmark, which tops the list on the SDG Index, is in the 143rd position for SDG 12 and the Central African Republic, which is at the bottom of the 2019 SDG Index, holds the 2nd best position on SDG 13 [52]. Yet, deeper quantitative and qualitative analyses of underlying interactions among targets and goals in specific sub-national contexts which can reveal further trade-offs, and/or co-benefits that are important to inform local policy design, policy mixes, and policy instruments (at the level of targets) are needed.

In this respect, this article is a first attempt to show how local, national, and international policy makers and bureaucrats can deliver on their promises by not only isolating the momenta and singling out some 
selected SDGs but also by situating potential positive interactions among SDGs and associated targets from a perspective of policy integration and policy mixes. It would be equally interesting to observe and analyze whether direct influence matrices filled by computational intelligence and policy experts would converge or diverge (and if so, why). Initiation of local policy mix designs and implementation of wide-ranging yet interacting and synergetic policy mixes and accompanying actions are needed globally to achieve the ambitious targets of the SDGs until the year 2030 .

\section{SUPPLEMENTARY MATERIAL}

The supplementary material on Multilayer Perceptron Network is available online at https://doi.org/10.20900/jsr20200006.

\section{DATA AVAILABILITY}

The dataset of the study is available from the authors upon reasonable request.

\section{CONFLICTS OF INTEREST}

The author declares that there is no conflict of interest.

\section{FUNDING}

This research was funded by the United Nations University Maastricht Economic and Social Research Institute on Innovation and Technology (UNU-MERIT) Agreement No. 606UU-907.

\section{ACKNOWLEDGMENTS}

The author would like to thank "Economic Complexity and Innovation" and "Sustainable Development, Innovation and Societal Transitions" research teams at UNU-MERIT for constructive comments received in UNU-MERIT Internal Conference 2019, held on 2019 Jun 26th and 27th, 2019, and the reviewers.

\section{REFERENCES}

1. Griggs D, Stafford Smith M, Rockström J, Öhman MC, Gaffney O, et al. An integrated framework for sustainable development goals. Ecol Soc. 2014;19(4):49.

2. Griggs DJ, Nilsson M, Stevance A, McCollum D. A guide to SDG interactions: from science to implementation. Paris (France): International Council for Science; 2017.

3. Hickel J. The contradiction of the sustainable development goals: Growth versus ecology on a finite planet. Sustain Dev. 2019;27(5):873-84.

4. Fu B, Wang S, Zhang J, Hou Z, Li J. Unravelling the complexity in achieving the 17 sustainable-development goals. Natl Sci Rev. 2019;6(3):386-8. 
5. Zhou X, Moinuddin M. Sustainable Development Goals Interlinkages and Network Analysis: A Practical Tool for SDG Integration and Policy Coherence. Kanagawa (Japan): Institute for Global Environmental Strategies; 2017.

6. UNDP. Untangling the complexity of the Sustainable Development Goals in Moldova. New York (NY, US): UNDP; 2018. Available from: https://undg.org/silofighters blog/untangling-the-complexity-of-the-sustainab le-development-goals-in-moldova/. Accessed 2019 Jul 30.

7. UNDP. Keep it simple: Complexity and the SDGs. New York (NY, US): UNDP Europe and Central Asia; 2018. Available from: http://www.eurasia.undp.org/content/rbec/en/home/blog/2018/keep-it-simple --complexity-and-the-sdgs.html. Accessed 2019 Jul 30.

8. Weitz N, Carlsen H, Nilsson M, Skånberg K. Towards systemic and contextual priority setting for implementing the 2030 Agenda. Sustain Sci. 2018;13(2):531-48.

9. Allen C, Metternicht G, Wiedmann T. Prioritising SDG targets: Assessing baselines, gaps and interlinkages. Sustain Sci. 2019;14(2):421-38.

10. Ospina-Forero L, Castañeda Ramos G, Guerrero OA. Estimating Networks of Sustainable Development Goals. SSRN 3385362 [Preprint]. 2019 May 9. doi: $10.2139 /$ ssrn.3385362

11. Le Blanc D. Towards integration at last? The sustainable development goals as a network of targets. Sustain Dev. 2015;23(3):176-87.

12. Stevance AS. Review of Targets for the Sustainable Development Goals: The Science Perspective. Paris (France): ICSU, ISSC; 2015.

13. IGES. SDG Interlinkages Analysis \& Visualisation Tool (V2.0). Kanagawa (Japan): IGES; 2018. Available from: https://sdginterlinkages.iges.jp/. Accessed 2019 Jul 30.

14. Nilsson M, Chisholm E, Griggs D, Howden-Chapman P, McCollum D, Messerli $\mathrm{P}$, et al. Mapping interactions between the sustainable development goals: lessons learned and ways forward. Sustain Sci. 2018;13(6):1489-503.

15. Nilsson M, Griggs D, Visbeck M. Policy: map the interactions between Sustainable Development Goals. Nature. 2016;534(7607):320.

16. Singh GG, Cisneros-Montemayor AM, Swartz W, Cheung W, Guy JA, Kenny TA, et al. A rapid assessment of co-benefits and trade-offs among Sustainable Development Goals. Mar Policy. 2018;93:223-31.

17. Waage J, Yap C, Bell S, Levy C, Mace G, Pegram T, et al. Governing the UN Sustainable Development Goals: interactions, infrastructures, and institutions. Lancet Glob Health. 2015;3(5):e251-2.

18. Pradhan P, Costa L, Rybski D, Lucht W, Kropp JP. A systematic study of Sustainable Development Goal (SDG) interactions. Earth's Future. 2017;5(11):1169-79.

19. Türkeli S, Wong PH, Yitbarek EA. Multiplex Learning: An Evidence-Based Approach to Design Policy Learning Networks in Sub-Saharan Africa for the SDGs. In: Africa and the Sustainable Development Goals 2020. Cham (Switzerland): Springer; 2020. p. 279-92. 
20. Dörgő G, Sebestyén V, Abonyi J. Evaluating the Interconnectedness of the Sustainable Development Goals Based on the Causality Analysis of Sustainability Indicators. Sustainability. 2018;10(10):3766.

21. Sachs J, Schmidt-Traub G, Kroll C, Lafortune G, Fuller G. SDG Index and Dashboards Report 2019. New York (NY, US): Bertelsmann Stiftung and Sustainable Development Solutions Network (SDSN); 2019.

22. Papadimitriou E, Neves AR, Becker W. JRC Statistical Audit of the Sustainable Development Goals Index and Dashboards. Brussels (Belgium): Publications Office of the European Union; 2019. EUR 29776 EN.

23. Lafortune G, Fuller G, Moreno J, Schmidt-Traub G, Kroll C. SDG Index and Dashboards Detailed Methodological paper. New York (NY, US): Bertelsmann Stiftung and Sustainable Development Solutions Network (SDSN); 2018.

24. Zadeh LA. Fuzzy sets. Inf Control. 1965;8(3):338-53.

25. Johnson RC. Making the neural-fuzzy connection. Electronic Engineering Times. 1993;765:33-4.

26. Kosaka M, Mizuno H, Sasaki T, Someya R, Hamada N. Applications of fuzzy logic/neural network to securities trading decision support system. In: Conference Proceedings 1991 IEEE International Conference on Systems, Man, and Cybernetics; 1991 Oct 13-16; Charlottesville, VA, USA. Piscataway (NJ, US): IEEE; 1991. p. 1913-8.

27. Stathacopoulou R, Magoulas GD, Grigoriadou M, Samarakou M. Neural-Fuzzy Knowledge Processing in Intelligent Learning Interactive Neuro-Fuzzy Expert System for Diagnosis of Leukemia. Glob J Comput Sci Tech. 2011;11:112-30.

28. Wong KW, Fung CC, Myers D. An integrated neural fuzzy approach with reduced fuzzy rules for well log analysis. Int J Fuzzy Syst. 2002;4(1):592-9.

29. Mocanu D. New AI method increases the power of artificial neural networks. 2018. Available from: https://www.tue.nl/en/news/news-overview/new-aimethod-increases-the-power-of-artificial-neural-networks/. Accessed 2019 Jun 30.

30. Hornik K, Stinchcombe M, White H. Multilayer feedforward networks are universal approximators. Neural Networks. 1989;2(5):359-66.

31. Werbos P. Beyond Regression: New Tools for Prediction and Analysis in the Behavioral Sciences [dissertation]. Cambrige (MA, US): Harvard University; 1974.

32. Rumelhart DE, Hinton GE, McClelland JL. A general framework for parallel distributed processing. In: Parallel distributed processing: Explorations in the microstructure of cognition. Cambrige (MA, US): MIT Press; 1986. p. $45-76$.

33. De Veaux RD, Psichogios DC, Ungar LH. A comparison of two nonparametric estimation schemes: MARS and neural networks. Comput Chem Eng. 1993;17(8):819-37.

34. Bartlett PL. The sample complexity of pattern classification with neural networks: the size of the weights is more important than the size of the network. IEEE Trans Information Theory. 1998;44(2):525-36. 
35. Ingrassia S, Morlini I. Neural network modeling for small datasets. Technometrics. 2005;47(3):297-311.

36. IBM. Multilayer Perceptron (MLP). IBM Knowledge Center. Available from: https://www.ibm.com/support/knowledgecenter/en/SSLVMB 24.0.0/spss/neur al network/idh_idd mlp variables.html. Accessed 2019 Jun 30.

37. Karkalos NE, Efkolidis N, Kyratsis P, Markopoulos AP. A comparative study between regression and neural networks for modeling Al6082-T6 alloy drilling. Machines. 2019;7(1):13.

38. Sargent DJ. Comparison of artificial neural networks with other statistical approaches: results from medical data sets. Cancer. 2001;91(S8):1636-42.

39. Ragin CC. Fuzzy-set social science. Chicago (IL, US): University of Chicago Press; 2000.

40. Rosa JL, editor. Artificial Neural Networks: Models and Applications. Norderstedt (Germany): BoD-Books on Demand; 2016.

41. Duperrin JC, Godet M. Methode de hierarchisation des elements d'un systeme. Rapport Economique du CEA. Paris (France): CEA; 1973. p. 45-51. French.

42. Godet M. The art of scenarios and strategic planning: tools and pitfalls. Technol Forecast Soc Change. 2000;65(1):3-22.

43. Saxena JP, Vrat P. Impact of indirect relationships in classification of variables-a micmac analysis for energy conservation. Syst Res. 1990;7(4):245-53.

44. Villacorta PJ, Masegosa AD, Castellanos D, Lamata MT. A linguistic approach to structural analysis in prospective studies. In: International Conference on Information Processing and Management of Uncertainty in Knowledge-Based Systems. Berlin, Heidelberg (Germany): Springer; 2012. p. 150-9.

45. Cai Y, Xia C. Interpretive Structural Analysis of Interrelationships among the Elements of Characteristic Agriculture Development in Chinese Rural Poverty Alleviation. Sustainability. 2018;10(3):786.

46. SDF Fund. Our Programmes. SDG Fund UN Initiative. 2019. Available from: https://www.sdgfund.org/programmes. Accessed 2019 Jun 30.

47. Carpenter SR, Bennett EM. Reconsideration of the planetary boundary for phosphorus. Environ Res Lett. 2011;6(1):014009.

48. Conant RT, Berdanier AB, Grace PR. Patterns and trends in nitrogen use and nitrogen recovery efficiency in world agriculture. Global Biogeochem Cy. 2013;27(2):558-66.

49. Hoekstra AY. The global dimension of water governance: Why the river basin approach is no longer sufficient and why cooperative action at global level is needed. Water. 2011;3(1):21-46.

50. Thomas RJ, Akhtar-Schuster M, Stringer LC, Marques MJ, Escadafal R, Abraham E, et al. Fertile ground? Options for a science-policy platform for land. Environ Sci Policy. 2012;16:122-35.

51. Cormier R, Elliott M. SMART marine goals, targets and management-Is SDG 14 operational or aspirational, is "Life Below Water" sinking or swimming? Mar Pollut Bull. 2017;123(1-2):28-33. 
52. Papadimitriou E, Neves AR, Becker W; European Commission's Joint Research Centre. Behind the Numbers: Joint Research Centre Audit of the SDG Index and Dashboards. Brussels (Belgium): EC JRC; 2019. Available from: https://sdgindex.org/news/behind-the-numbers:-joint-research-centre-audit-ofthe-sdg-index-and-dashboards/. Accessed 2019 Jun 30.

How to cite this article:

Türkeli S. Complexity and the Sustainable Development Goals: A Computational Intelligence Approach to Support Policy Mix Designs. J Sustain Res. 2020;2(1):e200006. https://doi.org/10.20900/jsr20200006 